\title{
Velhos e novos mitos do rural brasileiro
}

\author{
JOSÉ GRAZIANO DA SILVA
}

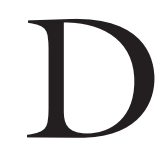

E FORMA MUITO sintética podemos dizer que nossas pesquisas no âmbito do Projeto Rurbano (1) nas suas fases I e II (2) contribuíram para derrubar alguns velhos mitos sobre o mundo rural brasileiro, mas que, infelizmente, podem estar servindo para criar outros novos.

Apresentaremos a seguir o que julgamos ser as principais conclusões obtidas pela pesquisa até o momento e um listado do que estamos nos propondo a pesquisar na fase III, iniciada em maio de 2001 e que se prolongará ate 2003.

\section{Os velhos mitos}

\section{"O rural é sinônimo de atraso"}

Mostramos que o rural não se opõe ao urbano enquanto símbolo da modernidade. Há no rural brasileiro ainda muito do atraso, da violência, por razões em parte históricas, relacionadas com a forma como foi feita a nossa colonização, baseada em grandes propriedades com trabalho escravo.

Mas há também a emergência de um novo rural, composto tanto pelo agribusiness quanto por novos sujeitos sociais: alguns neo-rurais, que exploram os nichos de mercados das novas atividades agrícolas (criação de escargot, plantas e animais exóticos etc.); moradores de condomínios rurais de alto padrão; loteamentos clandestinos que abrigam muitos empregados domésticos e aposentados, que não conseguem sobreviver na cidade com o salário mínimo que recebem; milhões de agricultores familiares e pluriativos, empregados agrícolas e não-agrícolas; e ainda milhões de sem-sem, excluídos e desorganizados, que além de não terem terra, também não têm emprego, não têm casa, não têm saúde, não têm educação e nem mesmo pertencem a uma organização como o MST para poderem expressar suas reivindicações.

Infelizmente essa categoria dos "sem-sem" vem crescendo rapidamente, em especial a partir da segunda metade dos anos 90. Os dados da PNAD de 1999 permitem uma aproximação desse contingente de pobres rurais: são quase três milhões de famílias (ou 15 milhões de pessoas) sobrevivendo com uma renda disponível per capita de US\$ 1 ou menos por dia (R\$ 34,60 mensais ao câmbio de setembro/99) (3). 
Mais de metade dessas famílias de pobres rurais tem suas rendas provenientes exclusivamente de atividades agrícolas: são famílias por conta própria (30\% do total) com áreas de terras insuficientes e/ou com condição de acesso à terra precária (parceiros, posseiros, cessionários) ou famílias de empregados agrícolas (25\%), a grande maioria sem carteira assinada.

Um terço dessas famílias de pobres rurais moram em domicílios sem luz elétrica, quase $90 \%$ não tem água canalizada, nem esgoto ou fossa séptica. Em quase metade dessas famílias mais pobres, o chefe ou pessoa de referência nunca freqüentou a escola ou não completou a primeira série do primeiro grau, podendo ser considerado como analfabeto.

Mas, infelizmente, nada disso é privilégio do "velho rural atrasado": das 4,3 milhões de famílias pobres residentes em áreas não-metropolitanas (pequenas e médias cidades), 70\% não têm também rede coletora de esgoto ou fossa séptica, quase $30 \%$ não possui água encanada, embora menos de $5 \%$ não tenha luz elétrica no domicílio. Em um terço delas o chefe de família também pode ser considerado analfabeto. Fica patente apenas a diferença entre rural e urbano no que diz respeito ao acesso à energia elétrica, que atualmente constitui um dos serviços básicos fundamentais, sem o qual fica difícil falar em modernidade. Infelizmente, essa diferença se explica em grande parte pela possibilidade dos pobres urbanos fazerem ligações clandestinas (gatos).

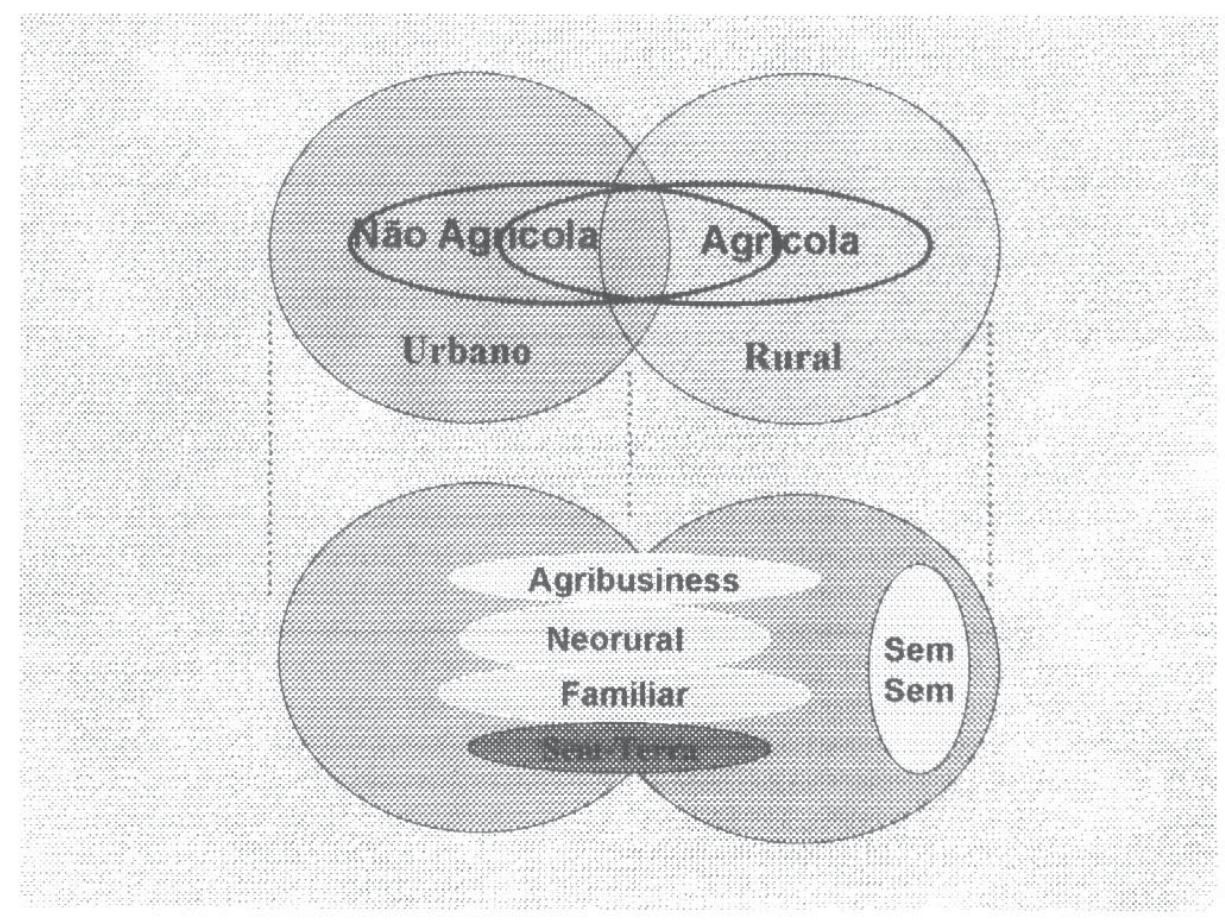

Figura 1. O novo rural 


\section{"O rural é predominantemente agrícola"}

Mostramos que um número crescente de pessoas que residem em áreas rurais estão hoje ocupadas em atividades não-agrícolas. Os dados da PNAD de 1999 também mostram que dos quase 15 milhões de pessoas economicamente ativas no meio rural brasileiro (exceto a região Norte), quase um terço - ou seja 4,6 mi-lhões de trabalhadores - estava trabalhando em ocupações rurais nãoagrícolas (ORNA): como serventes de pedreiro, motoristas, caseiros, empregadas domésticas etc. Mais importante que isso, as ocupações não-agrícolas cresceram na década dos 90 a uma taxa de $3,7 \%$ ao ano - mais que o dobro da taxa de crescimento populacional do país (ver tabela 1). Enquanto isso, o emprego agrícola, em função da mecanização das atividades de colheita dos nossos principais produtos, vem caindo cada vez mais rapidamente, a uma taxa de $-1,7 \%$ ao ano. Nossas projeções indicam que a continuar nesse ritmo, no ano 2014 a maioria dos residentes rurais do país estarão ocupados nessas atividades não-agrícolas. Em alguns estados, como São Paulo, isso já está ocorrendo atualmente.

Tabela 1 - Evolução da população do Brasil (a), 1981-99

\begin{tabular}{|c|c|c|c|c|c|c|c|c|c|c|}
\hline \multirow{3}{*}{$\begin{array}{l}\text { Emprego } \\
\text { Urbano }\end{array}$} & \multicolumn{4}{|c|}{ Pessoas (em milhões) } & \multicolumn{6}{|c|}{ Taxa crescimento (em \% a.a.) } \\
\hline & \multirow{2}{*}{$\begin{array}{r}1981 \\
85,2 \\
\end{array}$} & \multirow{2}{*}{$\begin{array}{r}1992 \\
113,4\end{array}$} & \multirow{2}{*}{$\frac{1996}{122,4}$} & \multirow{2}{*}{\begin{tabular}{|r|}
1999 \\
127,8
\end{tabular}} & \multicolumn{2}{|c|}{$1981-92$} & \multicolumn{2}{|c|}{$1992-99$} & \multicolumn{2}{|c|}{$1996-99$} \\
\hline & & & & & 2,6 & $* *$ & 1,7 & $\pi *$ & 1,4 & $\star \star \star \star$ \\
\hline Ocupados (b) & 31,7 & 46,5 & 50,4 & 52,8 & 3,6 & 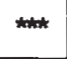 & 1,8 & tw & 1,5 & $m * *$ \\
\hline - agrícola & 2,6 & 3,7 & 3,4 & 3,4 & 3,3 & $\cdots$ & $-1,6$ & ** & $-0,2$ & \\
\hline - não-agrícola & 29,1 & 42,9 & 47,0 & 49,3 & 3,6 & 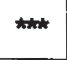 & 2,0 & *** & 1,6 & *** \\
\hline Rural & 34,5 & 32,0 & 31,7 & 32,6 & $-0,7$ & *to & 0,2 & 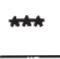 & 1,1 & +th \\
\hline Ocupados (b) & 13,8 & 14,7 & 13,9 & 14,9 & 0,6 & *** & $-0,2$ & thot & 2,1 & ** \\
\hline - agrícola & 10,7 & 11,2 & 9,9 & 10,2 & 0,4 & *** & $-1,7$ & th & 0,4 & \\
\hline - não-agrícola & 3,1 & 3,5 & 4,0 & 4,6 & 1,2 & $*+$ & 3,7 & * & 6,1 & $* *$ \\
\hline Total & 119,7 & 145,4 & 154,0 & 160,3 & 1,8 & *** & 1,4 & * & 1,3 & 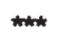 \\
\hline
\end{tabular}

Fonte: Tabulações especiais das PNADs de 1981 e de 1992-99, Projeto Rurbano, novembro 2000.

Notas: a) não inclui as áreas rurais da região Norte, exceto estado de Tocantins

b) PEA restrita, que exclui os não-remunerados que trabalham menos de 15 horas na semana e os que se dedicam exclusivamente ao autoconsumo. 
Outro dado que confirma a importância dessas atividades é que a soma dos rendimentos não-agrícolas das pessoas residentes nos espaços rurais superou em 1998 e 1999 os rendimentos provenientes exclusivamente das atividades agrícolas, segundo as PNADs. Ou seja, embora se saiba que as rendas agrícolas declaradas nas PNADs estão fortemente subestimadas, os rendimentos não-agrícolas dos residentes em espaços rurais no Brasil superam os rendimentos agrícolas totais desde 1998 (ver gráfico 1).

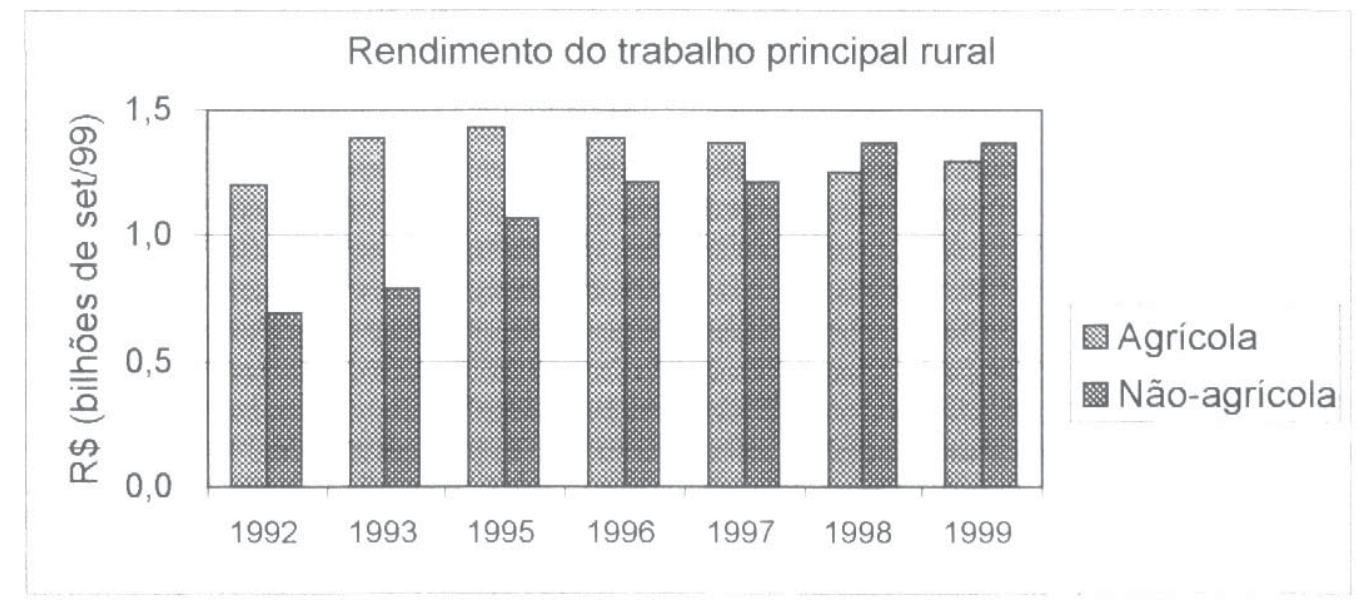

Gráfico 1. Evolução das rendas do trabalho principal das pessoas ocupadas no meio rural brasileiro, segundo o ramo de atividade. Brasil, 1992-99

\section{"O êxodo ruval é inexorável"}

As estatísticas mais recentes do Brasil rural revelam um paradoxo que interessa a toda sociedade: o emprego de natureza agrícola definha em praticamente todo o país, mas a população residente no campo voltou a crescer; ou pelo menos parou de cair. Esses sinais trocados sugerem que a dinâmica agrícola, embora fundamental, já não determina sozinha os rumos da demografia no campo. Esse novo cenário é explicado em parte pelo incremento do emprego não-agrícola no campo. Ao mesmo tempo, aumentou a massa de desempregados, inativos e aposentados que mantêm residência rural (ver gráfico 2). Se é verdade que ainda persiste algum êxodo, especialmente na região Sul, ele já não tem força para condicionar esse novo padrão emergente de recuperação das áreas rurais da maioria das regiões do país.

Os dados das PNADs mostram que a população rural chegou ao fundo do poço em 1996 (ano de contagem populacional), com 31,6 milhões de pessoas (4); a partir de então vem se recuperando, tendo atingido 32,6 milhões em 1999, ou seja, quase um milhão de pessoas a mais, significando uma taxa de crescimento 
anual da população rural de $1,1 \%$ ao ano, muito próximo do crescimento da população total de 1,3\% a.a. no mesmo período. No Nordeste, as duas taxas se igualaram ( $1,1 \%$ a.a.) e em São Paulo, o crescimento da população rural foi o dobro do total (3\% a.a. contra $1,5 \%$ a.a.), indicando uma verdadeira "volta aos campos" que não se confunde com uma volta às atividades agrícolas, até porque parte significativa dessa população passou a residir em áreas rurais próximas às grandes cidades do interior e da capital do estado. Na região Sul, no entanto, a população rural ainda mostra sinais de queda, especialmente naquelas áreas que denominamos de rural agropecuário ou rural profundo.

População rural não-economicamente ativa

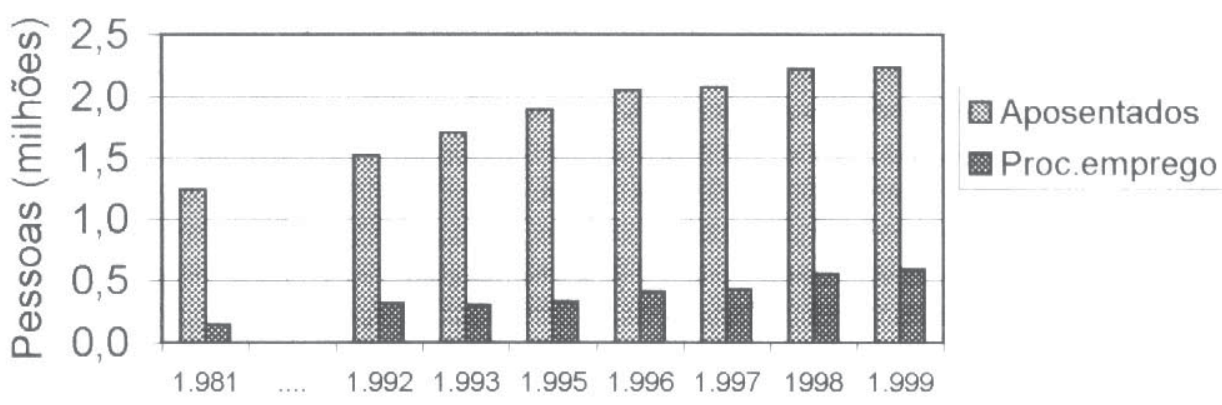

Gráfico 2. Evolução das pessoas inativas e residentes no meio rural, segundo o ramo de atividade. Brasil, 1981-99

É perigoso porém alimentar ilusões de que o mercado, por si só, tenha implementado um novo dinamismo sustentável no campo brasileiro. Mostramos que o inevitável é o êxodo agrícola o qual todavia pode ser, ao menos parcialmente, compensado com o crescimento da ORNA. Se a isso juntarmos os inativos (principalmente aposentados) que buscam as áreas rurais como local de residência, pode ser factível uma política de conter o significativo êxodo rural ainda existente em determinadas regiões do país, como o Sul.

\section{"O desenvolvimento agricola}

\section{leva ao desenvolvimento rural"}

Mostramos que as ocupações agrícolas são as que geram menor renda; e que o número de famílias agrícolas está diminuindo, pois elas não conseguem sobreviver apenas de rendas agrícolas. Nem mesmo o número das famílias pluriativas, nas quais seus membros combinam atividades agrícolas e não-agrícolas, 
vem aumentando. Dada a queda da renda proveniente das atividades agropecuárias, as famílias rurais brasileiras estão se tornando cada vez mais não-agrícolas, garantido sua sobrevivência mediante transferencias sociais (aposentadorias e pensões ) e em ocupações não-agrícolas.

Infelizmente não se pode comparar os rendimentos do período anterior ao Plano Real em função das distorções introduzidas pelas mudanças monetárias ocorridas na primeira metade dos anos 90. Mas os dados que dispomos para o período 1995-99, inteiramente sob vigência do Plano Real, apontam que para as famílias rurais de conta-própria agrícolas e pluriativas, a única parcela da renda familiar per capita que cresceu significativamente no período foi aquela proveniente das transferências sociais $(+6,7 \% \mathrm{e}+4,9 \%$ a.a., respectivamente). A fração da renda proveniente das atividades agrícolas (que representa $3 / 4$ ou mais da renda total dessas famílias) caiu tanto para as famílias rurais de conta-própria agrícola (-4,2\% a.a.) quanto para as pluriativas (-5,3\% a.a.). Para agravar ainda mais o quadro, as rendas não-agrícolas só cresceram para as famílias rurais de conta-própria nãoagrícola, permanecendo estagnadas para as pluriativas.

Em resumo, as famílias agrícolas e pluriativas ficaram mais pobres na segunda metade dos anos 90. E a queda das suas rendas per capita só não foi maior pela "compensação" crescente das transferências sociais de aposentadoria e pensões. É por essa razão que as famílias rurais estão se tornando crescentemente não-agrícolas.

\section{"A gestão das pequenas e médias propriedades rurais é familiar”}

Mostramos que estão crescendo as pequenas glebas (em geral com menos de 2 ha, tamanho do menor módulo rural) que têm a função muito mais de uma residência rural que de um estabelecimento agropecuário produtivo. E que a gestão das pequenas e médias propriedades agropecuárias está se individualizando, ficando o pai e/ou um dos filhos encarregado das atividades, enquanto os demais membros da família procuram outras formas de inserção produtiva, em geral fora da propriedade. Também uma parte cada vez maior das atividades agropecuárias antes realizadas no interior das propriedades estão sendo hoje contratadas externamente mediante serviços de terceiros, independentemente do tamanho das explorações. Ou seja, quem dirige os estabelecimentos agropecuários hoje não é mais a família como um todo, mas um (ou alguns ) de seus membros, o que coloca por terra a idéia de uma divisão social do trabalho assentada na disponibilidade de membros da família, distinta de uma divisão do trabalho capitalista.

A família rural típica não se reúne mais em torno da exploração agropecuária. O patrimônio familiar a ser preservado inclui as terras e, acima de tudo, a casa dos pais que se transforma numa espécie de base territorial, acolhendo os parentes próximos em algumas ocasiões festivas e tornando-se cada vez mais um ponto de 
refúgio nas crises, especialmente do desemprego, além de permanecer como alternativa de retorno para a velhice. Além disso, a gestão familiar inclui agora outros "negócios" não-agrícolas como parte de sua estratégia de sobrevivência (maioria dos casos) ou mesmo de acumulação. Em outras palavras, o centro das atividades da família deixou de ser a agricultura porque a família deixou de ser agrícola e se tornou pluriativa ou não-agrícola, embora permaneça residindo no campo.

\section{Os novos mitos}

\section{"ORNA é a solução para o desemprego"}

Uma análise desagregada das principais ocupações exercidas pelas pessoas residentes em áreas rurais no período 1992-99 aponta que quase todas as ocupações agropecuárias mostraram uma forte redução, especialmente aquelas mais genéricas como "trabalhador rural" e "empregado agrícola", que agregam os trabalhadores com menor grau de qualificação: cerca de um milhão de pessoas ocupadas a menos em 1999 em comparação a 1992.

Ao contrário, quase todas as ocupações rurais não-agrícolas apresentaram significativo crescimento no mesmo período, acumulando cerca de 1,1 milhão de pessoas a mais em 1999, como que "compensando" a queda das ocupações agrícolas. Destacam-se aqui, também, aquelas atividades pouco diferenciadas como os empregados em serviços domésticos, ajudantes de pedreiro e prestadores de serviços diversos, que somados perfazem um terço dos empregos rurais nãoagrícolas gerados no período.

Nossos trabalhos têm demonstrado que as atividades agrícolas continuam sendo a única alternativa para uma parte significativa da população rural, especialmente dos mais pobres. A parcela da força de trabalho agrícola que vai se tornando excedente pelo progresso tecnológico e pela reestruturação produtiva (substituição de cultivos, por exemplo) não encontra automaticamente ocupações não-agrícolas nas quais se engajar. E isso se deve fundamentalmente à inadequação dos atributos pessoais dos trabalhadores agrícolas que são dispensados (homens e mulheres de meia idade sem qualificação profissional e sem escolaridade formal) para exercerem as ORNAs disponíveis.

A maior parte das ocupações rurais não-agrícolas no Brasil, embora propiciem uma renda geralmente maior que as agrícolas e não sejam tão penosas como estas, são também trabalhos precários e de baixa qualificação. São basicamente serviços pessoais derivados da alta concentração da renda existente no Brasil e não da modernização das atividades agrícolas, nem da prestação de serviços voltados ao lazer e à preservação ambiental e muito menos de atividades nãoagrícolas produtivas do tipo agroindústria ou construção civil. Não é à-toa que encontramos em todas as regiões do país um forte crescimento do emprego doméstico de pessoas residindo na zona rural. O emprego doméstico desempenha 
hoje, para as mulheres, o papel da construção civil nas décadas passadas para os homens: é a porta de entrada na cidade por propiciar, além de um rendimento fixo, também um local de moradia. Especialmente para as mulheres rurais mais jovens, esta parece ter sido uma das poucas formas de inserção no mercado de trabalho nos anos 90, dadas as restrições crescentes à sua inserção na força de trabalho agrícola.

\section{"ORNA pode ser o motor do desenvolvimento nas regiões atrasadas”}

Uma das mais importantes contribuições do Projeto Rurbano foi mostrar que as novas dinâmicas em termos de geração de emprego e renda no meio rural brasileiro têm origem urbana, ou seja, são impulsadas por demandas não-agrícolas das populações urbanas, como é o caso das dinâmicas imobiliárias por residência no campo e dos serviços ligados ao lazer (turismo rural, preservação ambiental etc.).

Mostramos, também, que as ORNAs têm maior dinamismo justamente naquelas áreas rurais que têm uma agricultura desenvolvida e/ou estão mais próximas de grandes concentrações urbanas. Ou seja, nas regiões mais atrasadas, não há emprego agrícola e muito menos ocupações não-agrícolas. Assim, não há alternativa senão políticas compensatórias tais como as de renda mínima e de previdência social ativas, por exemplo. Além disso, há uma certa "reversão cíclica" à produção de subsistência nessas regiões mais atrasadas.

É o que parece estar ocorrendo no Nordeste: as ocupações agrícolas que vinham caindo, voltaram a crescer em 1999, em parte devido ao fim da seca que assolou a região nos últimos anos. A PNDA registrou aí mais 450 mil pessoas ocupadas nas áreas rurais em 1999 em relação ao ano anterior, a grande maioria das quais em atividades agrícolas não-remuneradas; e uma pequena redução da ORNA, situação similar ao que já havia acontecido entre 1993 e 1995. E essa "retomada da produção de subsistência" é financiada em grande parte pelas transferências socais de renda (sendo a principal delas a proveniente da aposentadoria rural) e pelo trabalho da mulher dos pequenos produtores que se tornam empregadas domésticas nas cidades da região e respondem por parte significativa das rendas monetárias das famílias de empregados rurais no Nordeste.

Em resumo, a falta de desenvolvimento rural na grande maioria das regiões "atrasadas" do país se deve fundamentalmente à falta de desenvolvimento das atividades não-agrícolas.

\section{"A reforma agrária não é mais viável"}

Mostramos que a agricultura não é mais a melhor forma de reinserção produtiva das famílias rurais sem terra, especialmente em função do baixo nível de renda gerado pelas as atividades tradicionais do setor. Pequenas áreas destinadas 
a produzir apenas arroz-feijão, assim como outros produtos agrícolas tradicionais, especialmente grãos, realmente não são mais viáveis. Mas, felizmente, as atividades agrícolas tradicionais também não são mais as únicas alternativas hoje disponíveis para a geração de ocupação e renda para as famílias rurais. Assim, é possível, e cada vez mais necessária, uma reforma agraria que crie novas formas de inserção produtiva para as famílias rurais, seja nas "novas atividades agrícolas", seja nas ORNAs. Por exemplo, na agroindústria doméstica, que lhes permita agregar valor à sua produção agropecuária, como também nos nichos de mercado propiciados pelas novas atividades agrícolas a que nos referimos anteriormente, ou até mesmo na prestação de serviços pessoais ou auxiliares de produção.

\section{"O novo ruval não precisa de regulação pública"}

Mostramos que o novo rural não é composto somente de amenidades, para usar uma expressão muito em moda nos países desenvolvidos. Como já dissemos, no Brasil, a maior parte das ORNAs, por exemplo, não passam de trabalhos precários, também de baixa remuneração Mostramos também que o crescimento dos desempregados no meio rural superou a taxa dos $10 \%$ ao ano no período 1992-99, apenas uma parte disso se devendo ao "retorno temporário" dos filhos que haviam migrado anteriormente para as cidades e voltam à casa dos pais até que encontrem outro trabalho. E há acima de tudo milhões de sem-sem para engrossar o êxodo rural assim que o crescimento industrial gerar novas oportunidades de trabalho nas cidades, porque são mínimas as condições de educação, saúde, habitação etc. de que dispõem localmente.

O traço comum entre o novo e o velho rural é a sua heterogeneidade, o que impede a generalização de situações locais específicas. Há novas formas de poluição e destruição da natureza associadas tanto às novas atividades agrícolas quanto às não-agrícolas. Mesmo nos condomínios rurais habitados por famílias de altas rendas, o tratamento do lixo e o esgotamento sanitário são muito precários na grande maioria dos casos. Da mesma maneira, embora até mesmo a empregada doméstica ganhe melhor que o bóia-fria, o maior nível de renda monetária propiciado pelas ORNAs nem sempre significa uma melhoria nas condições de vida e trabalho das famílias rurais não-agrícolas, especialmente quando isso implica a perda ao acesso à terra e à possibilidade de se combinar as rendas não-agrícolas com atividades de subsistência .

A emergência das novas funções (principalmente lazer e moradia) para o rural, somada à perda da regulação setorial (via políticas agrícolas e agrárias) resultante do esvaziamento do Estado nacional, deixou espaços que demandam novas formas de regulação públicas e privadas. É o caso exemplar das prefeituras batendo-se contra a proliferação desordenada dos condomínios rurais que não passam, no fundo, de novas formas de loteamentos clandestinos, que acabam demandando serviços como luz, água, coleta de lixo etc.; ou dos pesque-pagues, 
que têm de se submeter à fiscalização do Serviço de Saúde, do IBAMA e do INCRA, que possuem legislações contraditórias para enquadramentos de uma mesma atividade; ou então das novas reservas florestais fora da propriedade, que não são reconhecidas legalmente, embora tenham muito maior valor ecológico do que a manutenção de pequenas áreas descontínuas no interior das pequenas e médias propriedades rurais. Esses são apenas alguns exemplos gritantes de que precisamos de uma nova institucionalidade para o novo rural brasileiro, sem o quê corremos o risco de vê-lo envelhecer prematuramente.

\section{"O desenvolvimento local}

\section{leva automaticamente ao desenvolvimento"}

O novo enfoque do desenvolvimento local sustentável tem o inegável mérito de permitir a superação das já arcaicas dicotomias urbano/rural e agrícola/nãoagrícola. Como sabemos hoje, o rural, longe de ser apenas um espaço diferenciado pela relação com a terra - e mais amplamente com a natureza e o meio ambiente está profundamente relacionado ao urbano que lhe é contíguo. Também podemos dizer que as atividades agrícolas são profundamente transformadas pelas atividades não-agrícolas, de modo que não se pode falar na agricultura moderna deste final de século XX sem mencionar máquinas, fertilizantes, defensivos e toda as demais atividades não-agrícolas que lhe dão suporte.

Nossos trabalhos mostraram que a busca do desenvolvimento da agricultura mediante uma abordagem eminentemente setorial não é suficiente para levar ao desenvolvimento de uma região. Mostraram também que a falta de organização social - especialmente da sociedade civil - tem se caracterizado como uma barreira tão ou mais forte que a miséria das populações rurais, especialmente no momento em que a globalização revaloriza os espaços locais como arenas de participação política, econômica e social para os grupos organizados.

O enfoque do desenvolvimento local pressupõe que haja um mínimo de organização social para que os diferentes sujeitos sociais possam ser os reais protagonistas dos processos de transformação de seus lugares. Mas essa organização nem sempre existe em nível local; e quando existe, está restrita àqueles "velhos" atores sociais responsáveis, em última instância, pelo próprio subdesenvolvimento do local.

Nesse sentido podemos dizer que o desenvolvimento local sustentável precisa ser também entendido como desenvolvimento político no sentido de permitir uma melhor representação dos diversos atores, especialmente daqueles segmentos majoritários e que quase sempre são excluídos do processo pelas elites locais.

No caso brasileiro, por exemplo, as ações voltadas exclusivamente para o desenvolvimento agrícola, se bem tivessem logrado invejável modernização da base tecno-produtiva em alguma regiões do Centro-Sul do país, não se fizeram acompanhar pelo tão esperado desenvolvimento rural. Uma das principais razões 
para tanto foi a de privilegiar as dimensões tecnológicas e econômicas do processo de desenvolvimento rural, relegando a segundo plano as mudanças sociais e políticas como, por exemplo, a organização sindical dos trabalhadores rurais sem terra e dos pequenos produtores. Com a globalização, as disparidades hoje existentes em nosso país, seja em termos regionais, seja em relação à agricultura familiar vis-à-vis o agrobusiness, tendem a se acentuar ainda mais.

É fundamental mencionar que o escopo desses atores não se restringe aos produtores agrícolas - familiares ou não - por maior que seja a diferenciação deles. Devem ser considerados também os sujeitos urbanos que habitam o meio rural ou que simplesmente o tem como uma referência quase idílica de uma nova relação com a Natureza. Isso porque um outro componente, cada vez mais importante no fortalecimento dos espaços locais, tem sido as exigências e preocupações crescentes com a gestão e a conservação dos recursos naturais. Aqui também a organização dos atores sociais pode impulsionar a participação e a implementação de planos de desenvolvimento local voltados aos seus interesses, apesar de haver ainda muitas restrições quanto às formas de participação e representação, não só devido à sua pouca mobilização mas também à dificuldade de se ter todos os segmentos sociais devidamente representados, diante da presença de impedimentos e viéses operacionais vinculados às estruturas institucionais vigentes em nível local e à dominação das decisões pelos grupos mais fortes.

\section{$\mathrm{O}$ que falta pesquisar}

Iniciamos em maio de 2001 o que denominamos de Fase III do Projeto Rurbano, com os objetivos de:

- identificar os principais condicionantes de distribuição da renda das pessoas e das familias rurais e/ou agrícolas, tais como o grau e a intensidade da pluriatividade na agropecuária brasileira, a distribuição da terra segundo a posição da ocupação dos membros dos domicílios, o efeito das diferentes formas de acesso à terra (proprietário, parceiro, arrendatário e conta-própria) sobre os rendimentos das famílias, as diferentes formas de ocupação dos membros das famílias segundo sexo, grau de escolaridade, as características dos domicílios e sua disponibilidade de bens e serviços essenciais etc.;

- pesquisar a importância do trabalho doméstico como alternativa de ocupação e renda das famílias rurais, isolando essa categoria de trabalhadores como uma nova posição na ocupação e um outro tipo específico de atividade;

- pesquisar a importância da agroindústria e da indústria rural como geradoras de emprego e renda no meio rural, em particular no estado de São Paulo e em Minas Gerais, que têm um dos maiores parques agroindustriais do país;

- caracterizar as famílias rurais e/ou agrícolas com aposentados e/ou desocupados, com o objetivo de propor uma política previdenciária ativa para as regiões desfavorecidas do meio rural brasileiro; 
- caracterizar as famílias sem-terra em relação a renda e ocupação de seus membros em nível de grandes regiões e principais unidades da Federação, visando delimitar o que se poderia chamar o "núcleo duro" (core) da pobreza rural com o objetivo de subsidiar a política nacional de assentamentos rurais.

Além de tais temas, que decorrem das conclusões e resultados preliminares já obtidos, na Fase III do Projeto Rurbano pretende-se realizar alguns estudos de caso com vistas a:

- identificar as possíveis causas da subestimação das rendas variáveis nas PNADs, em particular das rendas agrícolas;

- aprofundar as dinâmicas de geração de ocupações não-agricolas identificadas em nível de Brasil para algumas regiões específicas que se destacaram nas análises anteriores (turismo no Nordeste; chácaras de recreio no Sudeste etc.);

- investigar a questão da identidade das familias rurais pluriativas e/ou nãoagricolas frente aos novos sujeitos sociais do novo mundo rural, entre eles caseiros, moradores de condomínios fechados, aposentados etc.;

- aprofundar o tema das relações entre o desenvolvimento local e poder local destacando a competência nos diferentes níveis de ação do poder público (municipal, estadual e federal), bem como quais seriam as principais formas de intervenção pública e privada sobre as áreas;

- avaliar o impacto ambiental e sócio-econômico das "novas" atividades desenvolvidas no meio rural, introduzindo a questão da legislação ambiental, trabalhista e a necessidade de um código do uso do solo, da água e de outros recursos naturais para a gestão do território rurbano;

- aprofundar o tema das politicas públicas para o novo rural brasileiro, com ênfase na política de turismo rural como alternativa de geração de novas oportunidades de negócios e ocupações no meio rural.

Para cumprir os objetivos descritos foram delineados 20 subprojetos de pesquisa, oito teses de doutoramento, sete dissertações de mestrado, além de vários projetos de iniciação científica. Nosso projeto de pesquisa envolve atualmente 45 pessoas entre professores universitários, profissionais liberais de várias origens e estudantes de graduação e pós-graduação, distribuídos por 20 instituições de pesquisa em 11 estados do país, 25 delas com título de doutor ou superior.

Além de estudos de caso, pretendemos, em 2002, iniciar a análise dos dados do Censo Demográfico de 2000, que nos possibilitarão um tratamento territorial inferior ao corte metro/não-metro permitido pelas PNADs, como, por exemplo, micro-regiões, bacias hidrográficas e até mesmo municípios. 


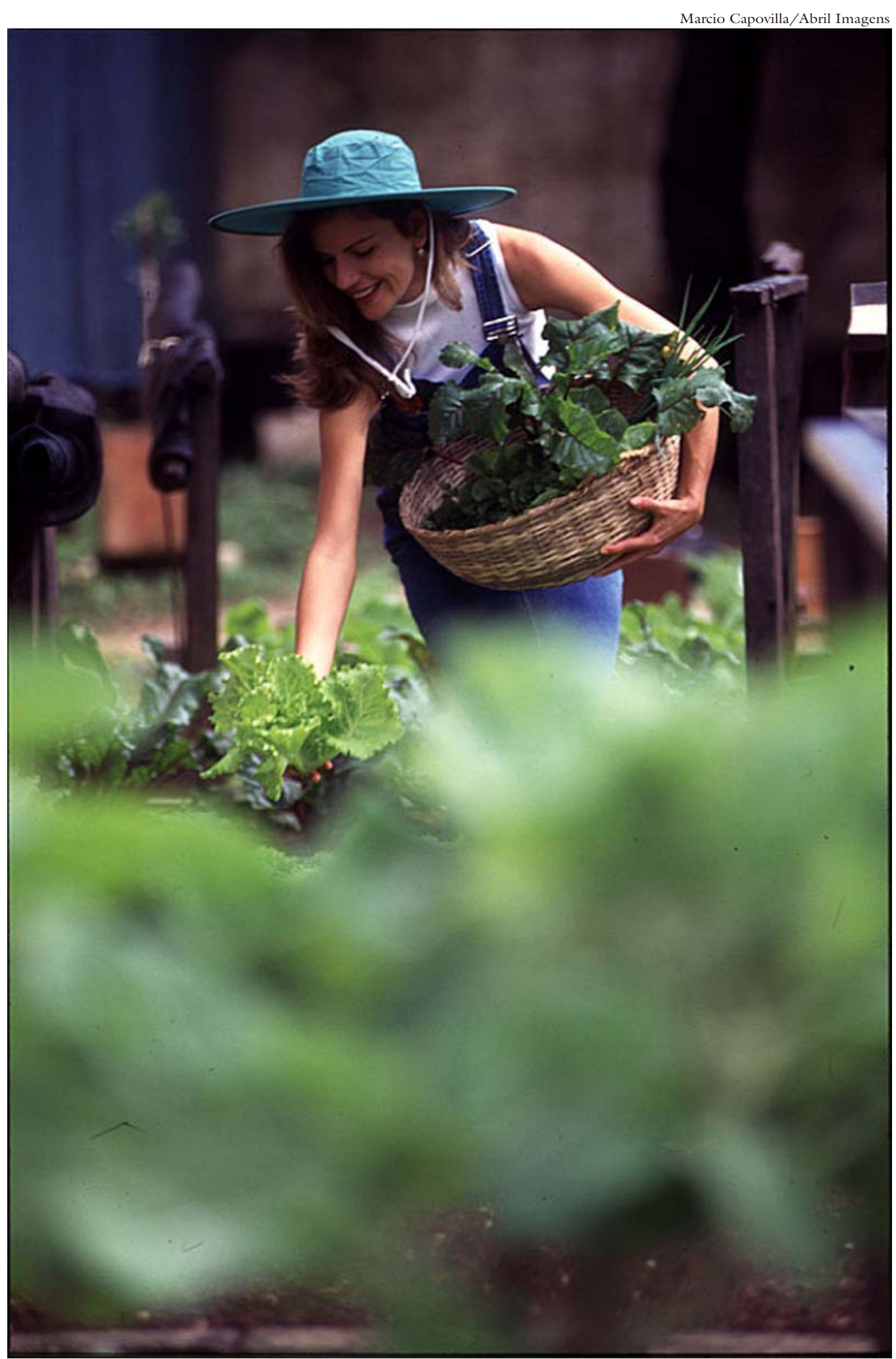

O rural está profundamente relacionado ao urbano que the é contiguo. 
Notas

1 Projeto temático denominado Caracterização do Novo Rural Brasileiro, 1981-95 que conta com financiamento parcial da FAPESP e PRONEX-CNPq, que pretende analisar as principais transformações ocorridas no meio rural em 11 unidades da Federação (PI, RN, AL, BA, MG, RJ, SP, PR, SC, RS e DF). Consulte nossa homepage na internet (http://www.eco.unicamp.br/projetos/rurbano.html).

$2 \mathrm{Na}$ fase I foram explorados basicamente os tipos de ocupações das pessoas residentes nas áreas rurais; na fase II, as rendas das famílias agrícolas, pluriativas e não-agrícolas residentes nas áreas rurais. As principais publicações estão disponíveis na nossa homepage e numa coletânea de quatro volumes organizada por C. Campanhola \& J. Graziano da Silva, O novo rural brasileiro: uma análise nacional e regional. Jaguariúna, EmbrapaMeio Ambiente/IE-Unicamp, 2000.

3 Imputando-se o valor do autoconsumo agrícola e descontando-se os pagamentos de aluguel e da prestação da casa própria, quando fosse o caso, essa metodologia adotada pelo Banco Mundial foi desenvolvida por M. Takagi; J. Graziano da Silva \& M. Del Grossi, Pobreza e fome: em busca de uma metodologia para quantificação do fenômeno no Brasil. Campinas, Instituto de Economia/Unicamp (texto para discussão 101, www.eco.unicamp.br/publicacoes).

4 Infelizmente são cada vez maiores as indicações de que os dados da contagem populacional estão fortemente subestimados. No caso das áreas rurais do interior de São Paulo, por exemplo, a subestimação fica evidente ao se constatar uma elevação generalizada nas taxas de crescimento populacional entre 1996 e 2000 após terem mostrado fortes quedas entre 1991 e 1996. Como a contagem de 1996 foi realizada em conjunto com o Censo Agropecuário de 1995-96 e há uma outra pesquisa para as áreas rurais paulistas no mesmo período (LUPA), é possível evidenciar as regiões mais afetadas.

José Graziano da Silva é professor titular de Economia Agrícola da Unicamp, bolsista do CNPq e consultor da Fundação Seade (graziano@eco.unicamp.br). 